\title{
Factors associated with primary transmission of multidrug-resistant tuberculosis compared with healthy controls in Henan Province, China
}

Wei-Bin Li ${ }^{1+}$, Yan-Qiu Zhang ${ }^{2+}$, Jin Xing ${ }^{2}$, Zhen-Ya Ma ${ }^{1}$, Ya-Hong Qu ${ }^{1}$ and Xin-Xu Li ${ }^{3 *}$

\begin{abstract}
Background: It is estimated that there are about 74,000 primary multidrug-resistant tuberculosis (MDR-TB) patients per year according to the prevalence of MDR-TB of 5.7\% among new TB patients in China. Thus, the risks of primary transmission of MDR-TB require further attention. This study aimed to identify the factors associated with primary transmission of MDR-TB in Henan province, where the number of new TB patients is ranked second highest in China.
\end{abstract}

Methods: A 1:1 matched case-control study was conducted in Henan, China. Cases were primary MDR-TB patients who were individually matched with a healthy control without TB from the same neighborhood. The study was conducted from July 2013 to June 2014. Both case and control were matched by age ( \pm 5 years) and sex. Conditional logistic regression was used to compute adjusted odds ratios (AORs) with corresponding 95\% confidence intervals (Cls) for risk factors associated with primary MDR-TB.

Results: For the study, 146 pairs of participants were recruited. The final multivariable logistic regression model disclosed that after adjusting for age and sex, primary MDR-TB cases were more likely to be single (AOR, 5.4; 95\% Cl, 1.4-20.7), earn an annual income of $\leq 12,000$ yuan (RMB) (AOR, 9.9; $95 \% \mathrm{Cl}, 2.0-48.1)$, experience more life pressure/stress (AOR, 10.8; 95\% $\mathrm{Cl}, 2.8-41.5)$, not be medically insured (AOR, 50.1; 95\% Cl, 8.2-306.8), and suffer from diabetes, cardiovascular disease or other respiratory diseases, or cancer (AOR, 57.1; 95\% Cl, 8.6-424.2).

Conclusions: In order to control primary transmission of MDR-TB in China, we recommend that improving the social support, living standards and medical security of the lower social class become a priority.

Keywords: Tuberculosis, Primary MDR-TB, Factors, Matched case-control, China

\section{Multilingual abstracts}

Please see Additional file 1 for translations of the abstract into the six official working languages of the United Nations.

\section{Background}

Multidrug-resistant tuberculosis (MDR-TB), defined as TB caused by strains of Mycobacterium tuberculosis that is resistant to at least isoniazid (INH) and rifampicin (RFP), is strongly related to irregular or weak treatment

\footnotetext{
* Correspondence: lixinxu@chinatb.org

${ }^{\dagger}$ Equal contributors

${ }^{3}$ National Center for Tuberculosis Control and Prevention, Chinese Center for Disease Control and Prevention, 155 Changbai Road, Changping District, Beijing 102206, PRC

Full list of author information is available at the end of the article
}

of TB [1-3]. The rates of MDR-TB in previously treated TB cases are significantly higher than in newly diagnosed TB cases [4-6]. Compared with acquired MDR-TB that is developed in the course of TB treatment, it is easy to neglect primary MDR-TB (defined as having no previous history of $\mathrm{TB}$ alongside primary infection with resistant bacteria) for MDR-TB control because of the lower rates associated with it. The proportion of MDR$\mathrm{TB}$ is $5.7 \%$ in new $\mathrm{TB}$ cases and $25.6 \%$ in previously treated TB cases in China $[7,8]$. However, lower rates don't necessarily equate with fewer cases. About 870,000 new cases and 54,000 retreatment cases were notified in China in 2010, which suggests that the estimated number of primary MDR-TB cases is higher than that of acquired MDR-TB cases.

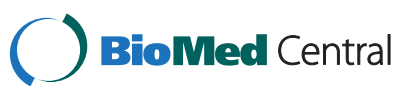


Nosocomial transmission of MDR-TB among human immunodeficiency virus (HIV) infected patients and health workers as well as household transmission of MDR-TB have been investigated since the 1990s [9-11]. In recent years, the extensive person-to-person transmission of MDR-TB has been of concern in many countries. A study in Papua New Guinea showed transmission of MDR-TB, whilst another study in Spain suggested that MDR-TB in a low-incidence region showed a high rate of transmission $[12,13]$. China also documented that transmission of MDR-TB strains was a serious concern in big cities and some rural areas [14,15]. The transmission of MDR-TB in the general population is a huge public health challenge for MDR-TB control. Thus, prompt, effective, and appropriate actions to interrupt the transmission must be urgently taken.

However, research on independent or dependent determinants of primary MDR-TB is scanty, and research on the risk factors in a representative data associated with primary MDR-TB is scarce in China. Although a study reported a high rate of primary MDR-TB in a general population with no identifiable risk factors for MDR-TB [16], more studies on primary MDR-TB are needed to verify this. In 2012, the number of new TB cases in Henan province ranked second highest in China. Therefore, we aimed to explore the risk factors possibly associated with primary transmission of MDRTB in Henan, such as sociodemographic characteristics, daily behaviors, and medical experiences, and provide insights into effective primary MDR-TB control, i.e. interrupting transmission of MDR-TB in the general population in China.

\section{Methods}

Between July 2013 and June 2014, 146 primary MDR-TB cases were selected in Henan. The cases were confirmed by five prefecture-level TB dispensaries that implemented the MDR-TB control programs of the Global Fund, and by a prefecture-level TB dispensary that implemented the MDR-TB control program of the Bill \& Melinda Gates Foundation. All MDR-TB cases were identified by the laboratories of these prefecture-level TB dispensaries, using sputum culture and drug susceptibility testing (DST), with the proportion method for INH, RFP, ethambutol, and streptomycin, following the Guidelines for Surveillance of Drug Resistance in Tuberculosis (Second Edition) published by the World Health Organization (WHO) [17]. All laboratories of these prefecture-level $\mathrm{TB}$ dispensaries were accredited to diagnose MDR-TB by the TB reference laboratory of the Henan Center for Disease Control and Prevention (Henan CDC).

Each primary MDR-TB case was individually matched with a healthy control using the local population management system. The candidates for each control were selected from the same neighborhood of each case i.e. living in the nearest village or community. The age ( \pm 5 years) and gender of the control was matched to its corresponding case. The matched control was included if he or she did not have confirmed TB or any other pulmonary disease, as according to the diagnostic criteria of the National Tuberculosis Control Program in China [18], and if he or she had the most similar matching conditions to the case. All participants were systematically tested for HIV.

A structured questionnaire was developed and pretested before interviews with study participants began (see Additional file 2). This study was evaluated and approved by the Ethics Review Committees (ERCs) of both the Henan CDC and the China CDC. Before the interviews, all participants were asked for their written informed consent. The questionnaire covered sociodemographic characteristics, daily behaviors, and medical experiences of primary MDR-TB cases in the year prior to them becoming patients, and of healthy controls in the same year. Office workers/jobs that require mental skills and manual labor workers are referred to as skilled and unskilled workers, respectively, in this study. All the interviews were conducted in participants' homes, rooms of local CDCs, or TB dispensaries, as chosen by the participants. The matched participants were interviewed on the same day by the same interviewer. Privacy was ensured while interviews were being conducted.

A conditional logistic regression model was used to account for the matched case-control study design. All analyses were performed using the SAS statistical package (version 9.2, SAS Institute, Inc., Cary, NC). Univariable analysis was done for computing unadjusted matched odds ratios (ORs) and their 95\% confidence intervals (CIs). The level of significance was assessed by the Wald $\chi^{2}$ test. Variables with $p$-values $<0.05$ were entered into a multivariable conditional logistic regression model to simultaneously examine their independent effects (adjusted ORs, AORs) through stepwise deletion of variables. The final model was obtained until all predictors left had $p$-values $<0.05$.

\section{Results}

As shown in Table 1, 146 primary MDR-TB cases and matched controls were enrolled in the study. The mean ages of both groups were $48 \pm 17$ years old and $48 \pm$ 16 years old, respectively, and $66.7 \%$ were males. Compared with controls, primary MDR-TB cases were more likely to have an education level of middle school or below (43.1\% versus $17.6 \%)$ and be single (33.3\% versus 17.6\%). There were similar proportions of employment between primary MDR-TB cases and controls: 19.6\% and $13.7 \%$ were unemployed, $31.4 \%$ and $39.2 \%$ were 
Table 1 Sociodemographic characteristics of primary MDR-TB cases and controls, sex and age ( \pm 5 years) matched

\begin{tabular}{|c|c|c|c|c|c|c|}
\hline Variables & & $\begin{array}{l}\text { Primary MDR-TB cases } \\
n(\%)\end{array}$ & $\begin{array}{l}\text { Controls } \\
n(\%)\end{array}$ & $\begin{array}{l}\text { Wald } \\
x^{2} \text { value }\end{array}$ & $p$-value & $\operatorname{COR}(95 \% \mathrm{Cl})$ \\
\hline Total (N) & & $146(100.00)$ & $146(100.00)$ & NA & NA & NA \\
\hline \multirow[t]{2}{*}{ Sex } & Male & $97(66.67)$ & $97(66.67)$ & NA & NA & NA \\
\hline & Female & $49(33.33)$ & 49 (33.33) & NA & NA & NA \\
\hline \multirow[t]{2}{*}{ Age (years) } & (mean \pm standard deviation) & $48 \pm 17$ & $48 \pm 16$ & NA & NA & NA \\
\hline & {$[$ median (min, max)] } & $48(18,79)$ & $49(18,77)$ & NA & NA & NA \\
\hline \multirow[t]{2}{*}{ Education } & Middle school and above & $83(56.86)$ & $120(82.35)$ & & & 1.00 \\
\hline & Illiterate or elementary school & $63(43.14)$ & $26(17.65)$ & 6.78 & 0.0092 & $4.25(1.43-12.63)$ \\
\hline \multirow[t]{2}{*}{ Single } & No & $97(66.67)$ & $120(82.35)$ & & & 1.00 \\
\hline & Yes & $49(33.33)$ & $26(17.65)$ & 4.32 & 0.0377 & $5.00(1.10-22.81)$ \\
\hline \multirow[t]{4}{*}{ Employment } & Unemployed & $29(19.61)$ & $20(13.73)$ & & & 1.00 \\
\hline & Skilled or unskilled worker & $46(31.37)$ & $57(39.22)$ & 1.02 & 0.3132 & $0.53(0.15-1.82)$ \\
\hline & Migrant worker & $37(25.49)$ & $34(23.53)$ & 0.17 & 0.6763 & $0.76(0.21-2.79)$ \\
\hline & Farmer & $34(23.53)$ & $34(23.53)$ & 0.35 & 0.5554 & $0.62(0.13-3.01)$ \\
\hline \multirow[t]{2}{*}{ Annual income (RMB) } & $>12,000$ yuan & $26(17.65)$ & $72(49.02)$ & & & 1.00 \\
\hline & $\leq 12,000$ yuan & $120(82.35)$ & $74(50.98)$ & 8.83 & 0.0030 & $6.33(1.87-21.40)$ \\
\hline \multirow[t]{2}{*}{ Area of residence } & Urban & $57(39.22)$ & $77(52.94)$ & & & 1.00 \\
\hline & Rural & $89(60.78)$ & $69(47.06)$ & 2.24 & 0.1344 & $2.00(0.81-4.96)$ \\
\hline \multirow[t]{2}{*}{ Size of living space } & $\geq 40 \mathrm{~m}^{2}$ & $46(31.37)$ & $86(58.82)$ & & & 1.00 \\
\hline & $<40 \mathrm{~m}^{2}$ & $100(68.63)$ & $80(41.18)$ & 6.34 & 0.0188 & $3.00(1.28-7.06)$ \\
\hline \multirow[t]{2}{*}{ Floor in building of living space } & Second floor and above & $40(27.45)$ & $83(56.86)$ & & & \\
\hline & Below the second floor & $106(72.55)$ & $63(43.14)$ & 7.69 & 0.0056 & $4.00(1.50-10.66)$ \\
\hline
\end{tabular}

NOTE: COR: crude odds ratio; Cl: confidence interval; NA: not applicable.

skilled or unskilled workers, $25.5 \%$ and $23.5 \%$ were migrant workers, and $23.5 \%$ and $23.5 \%$ were farmers, respectively. Compared with controls, primary MDRTB cases were more likely to earn less than 12,000 yuan (RMB) per year (82.4\% versus $51.0 \%)$ and live in a room smaller than $40 \mathrm{~m}^{2}$ (68.6\% versus $\left.41.2 \%\right)$.

The univariable ORs with $95 \%$ CIs for potential risk factors were evaluated for their association with primary MDR-TB (see Tables 1, 2, and 3). Compared with controls, risk factors significantly associated with primary MDR-TB were illiteracy or primary school education (OR, 4.25; 95\% CI, 1.43-12.63), being single (OR, 5.00; $95 \% \mathrm{CI}, 1.10-22.81)$, an annual income $\leq 12,000$ yuan (RMB) (OR, 6.33; 95\% CI, 1.87-21.40), living space < $40 \mathrm{~m}^{2}$ (OR, 3.00; 95\% CI, 1.28-7.06), living below the second floor (OR, 4.00; 95\% CI, 1.50-10.66), body mass index $\leq 20$ (OR, 3.75; 95\% CI, 1.23-11.30), eating fruit once in intervals of $>7$ days (OR, 3.50; 95\% CI, 1.1510.63), exercising once in intervals of $\geq 2$ days (OR, 4.33; 95\% CI, 1.24-15.20), more life pressure/stress (OR, 4.00; 95\% CI, 1.50-10.66), not being medically insured (OR, 8.00; 95\% CI, 1.84-34.79), and suffering from diabetes, cardiovascular disease, other respiratory diseases, or cancer (OR, 12.00; 95\% CI, 1.56-92.27).
As shown in Table 4, risk factors independently associated with primary MDR-TB were being single (AOR, 5.37; 95\% CI, 1.39-20.67), earning an annual income $\leq$ 12,000 yuan (RMB) (AOR, 9.93; 95\% CI, 2.05-48.11), having more life pressure/stress (AOR, 10.80; 95\% CI, 2.81-41.52), not being medically insured (AOR, 50.07; 95\% CI, 8.17-306.81), and suffering from diabetes, cardiovascular disease, other respiratory diseases, or cancer (AOR, 57.05; 95\% CI, 8.59-424.17).

\section{Discussion}

Findings from this study showed that being single, earning a low income, having mental stress, lacking medical insurance, and suffering from a chronic debilitating disease were potential risk factors associated with primary MDR-TB. However, risk factors of nosocomial transmission and close contact were not found. Although many risk factors associated with MDR-TB were found in many studies [1-3], only one study researched risk factors associated with primary MDR-TB, with no identifiable risk factors reported prior to this [16]. Therefore, our study has value and provided a timely report on the risk factors of primary MDR-TB. 
Table 2 Daily behaviors of primary MDR-TB cases and controls, sex and age ( \pm 5 years) matched

\begin{tabular}{|c|c|c|c|c|c|c|}
\hline Variables & & $\begin{array}{l}\text { Primary MDR-TB cases } \\
n(\%)\end{array}$ & $\begin{array}{l}\text { Controls } \\
n(\%)\end{array}$ & $\begin{array}{l}\text { Wald } \\
X^{2} \\
\text { value }\end{array}$ & $p$-value & COR $(95 \% \mathrm{Cl})$ \\
\hline Total (N) & & $146(100.00)$ & $146(100.00)$ & NA & NA & NA \\
\hline \multirow[t]{2}{*}{ Body mass index } & $>20$ & $92(62.75)$ & $123(84.31)$ & & & 1.00 \\
\hline & $\leq 20$ & $54(37.25)$ & $23(15.69)$ & 5.52 & 0.0188 & $3.75(1.23-11.30)$ \\
\hline \multirow[t]{2}{*}{ Interval of days of eating meat } & $\leq 1$ & $92(62.75)$ & $103(70.59)$ & & & 1.00 \\
\hline & $>1$ & $54(37.25)$ & $43(29.41)$ & 0.61 & 0.4346 & $1.36(0.63-2.97)$ \\
\hline \multirow[t]{2}{*}{ Interval of days of eating coarse food grain } & $\leq 2$ & $80(54.90)$ & $86(58.82)$ & & & 1.00 \\
\hline & $>2$ & $66(45.10)$ & $60(41.18)$ & 0.28 & 0.5943 & $1.33(0.46-3.84)$ \\
\hline \multirow[t]{2}{*}{ Interval of days of eating fruit } & $\leq 7$ & $94(64.71)$ & $123(84.31)$ & & & 1.00 \\
\hline & $>7$ & $52(35.29)$ & $23(15.69)$ & 4.88 & 0.0271 & $3.50(1.15-10.63)$ \\
\hline \multirow[t]{2}{*}{ Hours of sleep each night } & $>7$ & $89(60.78)$ & $86(58.82)$ & & & 1.00 \\
\hline & $\leq 7$ & $57(39.22)$ & $60(41.18)$ & 0.04 & 0.8475 & $0.93(0.44-1.98)$ \\
\hline \multirow[t]{2}{*}{ Interval of days of doing physical exercise } & $<2$ & $20(13.73)$ & $49(33.33)$ & & & 1.00 \\
\hline & $\geq 2$ & $126(86.27)$ & $97(66.67)$ & 5.24 & 0.0221 & $4.33(1.24-15.20)$ \\
\hline \multirow[t]{2}{*}{ More life pressure/stress } & No & $86(58.82)$ & $129(88.24)$ & & & 1.00 \\
\hline & Yes & $60(41.18)$ & $17(11.76)$ & 7.69 & 0.0056 & $4.00(1.50-10.66)$ \\
\hline \multirow[t]{2}{*}{ Interval of weeks of going to crowded fields } & $>1$ & $92(62.75)$ & $103(70.59)$ & & & 1.00 \\
\hline & $\leq 1$ & $54(37.25)$ & $43(29.41)$ & 0.98 & 0.3226 & $1.67(0.61-4.59)$ \\
\hline \multirow[t]{2}{*}{ Never smoking } & Yes & $92(62.75)$ & $83(56.86)$ & & & 1.00 \\
\hline & No & $54(37.25)$ & $63(43.14)$ & 0.47 & 0.4931 & $0.73(0.29-1.81)$ \\
\hline \multirow[t]{2}{*}{ Never drinking alcohol } & Yes & $72(49.02)$ & $66(45.10)$ & & & 1.00 \\
\hline & No & $74(50.98)$ & $80(54.90)$ & 0.22 & 0.6380 & $0.80(0.32-2.03)$ \\
\hline
\end{tabular}

NOTE: COR: crude odds ratio; Cl: confidence interval; NA: not applicable.

Marital status, as one kind of sociodemographic characteristics, is often related to diseases, including TB. Studies in Henan and Hong Kong highlighted that marital status was independently associated with TB $[19,20]$. Being single was a risk factor for primary MDR-TB in this study, which was in agreement with many other studies that showed that single persons were more likely to develop TB $[21,22]$. Although there isn't an identifiable biological relationship between marital status and $\mathrm{TB}$, single persons are more likely to lack social support

Table 3 Medical experiences of primary MDR-TB cases and controls, sex and age ( \pm 5 years) matched

\begin{tabular}{|c|c|c|c|c|c|c|}
\hline Variables & & $\begin{array}{l}\text { Primary MDR-TB cases } \\
n(\%)\end{array}$ & $\begin{array}{l}\text { Controls } \\
n(\%)\end{array}$ & $\begin{array}{l}\text { Wald } \\
X^{2} \\
\text { value }\end{array}$ & $p$-value & $\operatorname{COR}(95 \% \mathrm{Cl})$ \\
\hline Total (N) & & $146(100.00)$ & $146(100.00)$ & NA & NA & NA \\
\hline \multirow[t]{2}{*}{ Medically insured } & Yes & $97(66.67)$ & $137(94.12)$ & & & 1.00 \\
\hline & $\mathrm{No}$ & $49(33.33)$ & $9(5.88)$ & 7.69 & 0.0056 & $8.00(1.84-34.79)$ \\
\hline \multirow[t]{2}{*}{ Being vaccinated with BCG vaccine } & Yes & $77(52.94)$ & $92(62.75)$ & & & 1.00 \\
\hline & No & $69(47.06)$ & $54(37.25)$ & 1.28 & 0.2571 & $1.71(0.68-4.35)$ \\
\hline \multirow[t]{2}{*}{ Ever visiting hospitals } & No & $106(72.55)$ & $94(64.71)$ & & & 1.00 \\
\hline & Yes & $40(27.45)$ & $52(35.29)$ & 0.79 & 0.3744 & $0.67(0.27-1.63)$ \\
\hline \multirow{2}{*}{$\begin{array}{l}\text { Suffering from diabetes, cardiovascular disease, } \\
\text { other respiratory diseases, or cancer }\end{array}$} & No & $109(74.51)$ & $140(96.08)$ & & & 1.00 \\
\hline & Yes & $37(25.49)$ & $6(3.92)$ & 5.70 & 0.0170 & $12.00(1.56-92.27)$ \\
\hline \multirow[t]{2}{*}{ Possible exposure to TB cases } & No & $80(54.90)$ & $86(58.82)$ & & & 1.00 \\
\hline & Yes & $66(45.10)$ & $60(41.18)$ & 0.13 & 0.7156 & $1.14(0.56-2.34)$ \\
\hline
\end{tabular}

NOTE: COR: crude odds ratio; Cl: confidence interval; NA: not applicable 
Table 4 Multivariable conditional logistic regression model showing risk factors independently associated with primary MDR-TB

\begin{tabular}{|c|c|c|c|}
\hline Variables & Wald $x^{2}$ value & $p$-value & AOR $(95 \% \mathrm{Cl})$ \\
\hline Single $(\mathrm{No}=0, \mathrm{Yes}=1)$ & 5.96 & 0.0146 & $5.37(1.39-20.67)$ \\
\hline Annual income $(\mathrm{RMB})(>12,000$ yuan $=0, \leq 12,000$ yuan $=1)$ & 8.13 & 0.0044 & $9.93(2.05-48.11)$ \\
\hline More life pressure/stress ( $\mathrm{No}=0$, Yes $=1$ ) & 12.00 & 0.0005 & $10.80(2.81-41.52)$ \\
\hline Being medically insured (Yes $=0, \mathrm{No}=1$ ) & 8.76 & 0.0031 & $50.07(8.17-306.81)$ \\
\hline Suffering from diabetes, cardiovascular disease, other respiratory diseases, or cancer ( $\mathrm{No}=0$, Yes $=1$ ) & 6.46 & 0.0110 & $57.05(8.59-424.17)$ \\
\hline
\end{tabular}

NOTE: AOR: adjusted odds ratio; $\mathrm{Cl}$, confidence interval.

or be involved in high-risk behaviors, such as alcohol consumption, which potentially leaves them exposed to higher risks of infection of TB or MDR-TB than those with other marital statuses $[23,24]$.

Like marital status, income levels are also interrelated with disease and health. In 2011, the WHO reported that most low-income countries had high TB and MDRTB rates [8]. A study in China suggested that low household economic conditions were associated with TB [19], and studies in Turkey and China found that a low socioeconomic status or poverty were associated with MDR-TB $[3,25]$. In this study, low income was also a risk factor associated with primary MDR-TB. Consequently, we infer that it is easy for TB patients in low-income communities to acquire MDR-TB because there is a lack of good medical services. With the increase of acquired MDR-TB patients in low-income communities, the general population has higher chances of contracting MDR-TB. In other words, inhabitants of low-income communities are more likely to become primary MDR-TB patients. This finding also suggests that primary transmission of MDR-TB is not extensive in the general population and still confined to low-income communities.

This study found that those who had high life pressures/stress were more likely to be primary MDR-TB patients, which was not shown in previous studies on MDR-TB [1-6]. China's development comes an increasing pressure that can trigger higher levels of mental stress in both low-income and high-income groups. It is known that mental stress can affect health by inducing immunologic and cardiovascular changes [26,27]. If mental stress develops into a severe mental illness, it might become a risk factor associated with TB [28]. Therefore, we speculate that mental stress induced by heavy life pressures can suppress the body's immune system and reduce the body's resistance, giving way to disease, such as infections of the upper respiratory tract [29], thus creating opportunities for the transmission of MDR-TB.

Our study also found that a lack of medical insurance was another risk factor associated with primary MDRTB. Many studies in China showed that not having medical insurance influenced a patient's access to TB care, due to the high cost of drugs, or led to failure of anti-TB treatment $[30,31]$. This might also indicate that medical insurance affects medical-seeking behaviors and medical services, and perhaps TB is representative of many diseases impacted by medical insurance. Most people without medical insurance in China probably delay medical-seeking behaviors, which worsen conditions in the body and unavoidably erode its defense mechanisms. Therefore, it is easy to understand that those who cannot afford medical insurance are more likely to be infected with MDR-TB.

Among the risk factors independently associated with primary MDR-TB in our study, suffering from diabetes, cardiovascular disease, other respiratory diseases, or cancer was another biologic risk factor. All these diseases fall into the chronic debilitating disease category. Previous studies confirmed that chronic debilitating diseases, such as diabetes, chronic respiratory diseases, and solidorgan malignancy, were risk factors for TB [32-34]. Another study reported that the impaired immunity in type 2 diabetes possibly increased susceptibility to infection with resistant strains of TB [35], which is consistent with our finding. Chronic debilitating diseases that can impair or suppress the body's immunity potentially increase the risks for primary MDR-TB.

The independent risk factors for primary MDR-TB in our study are related to sociodemographic characteristics, daily behaviors, and medical experiences. This points to the fact that the risk factors associated with TB in general are not too dissimilar to risk factors associated with MDR$\mathrm{TB}$, perhaps because primary MDR-TB is one of the subgroups of TB. Therefore, it seems that usual TB control measures would also be applicable to primary MDR-TB patients. Despite this, the findings of this study can provide specific clues for monitoring new TB cases with high risk factors for MDR-TB, and even identifying MDR-TB transmission hotspots in the general population [36]. The study can also provide specific clues for improving the integrated, comprehensive, interventional response packages that are used to control primary transmission of MDR-TB. An effective way of doing this is enhancing the social support, living standards, and medical security of the lower social class in China. 
Before summing up the main points of this study, we must outline its limitations. We collected data of primary MDR-TB cases and healthy controls in previous years, so recall biases were unavoidable and potentially affected the results. Data such as annual income, size of living space, and interval of days when certain foods were eaten might be inaccurate as it was collected by self-reporting. Additionally, there were some primary MDR-TB cases who were from rural areas adjacent to urban areas, but as we could not find appropriate healthy controls from their areas (according to their age and gender), we had to select the controls from the urban areas. Despite these limitations, our study provided some useful information for understanding risk factors of primary MDR-TB in China.

\section{Conclusion}

This matched case-control study identified risk factors associated with primary MDR-TB in Henan province, China. These included being single, having a low income, being mentally stressed, not being medically insured, and suffering from a chronic debilitating disease. On the contrary, other risk factors such as nosocomial transmission and close contact were not found. Perhaps it can be inferred from these findings that, currently, primary transmission of MDR-TB is not confined to nosocomial transmission and close contact, but is confined to low-income groups in the general population. These findings can be helpful to identify new TB cases with high risk factors for primary MDR-TB, and to improve the comprehensive, interventional response packages that are used to control primary MDR-TB by improving social support, living standards, and medical security of lower social groups in China.

\section{Additional files}

Additional file 1: Multilingual abstracts in the six official working languages of the United Nations.

Additional file 2: The structured questionnaire.

\section{Competing interests}

The authors declare that they have no competing interests.

\section{Authors' contributions}

Conceived and designed the experiments: W-B L, Y-Q Z, X-X L. Performed the experiments: $W-B L, Y-Q Z, J X, Z-Y, M, Y-H ~ Q$. Analyzed the data: $W-B L$, Y-Q Z, X-X L. Contributed reagents/materials/analysis tools: $X-X$ L. Provided constructive opinions and suggestions: J X, Z-Y M, Y-H Q. Wrote the paper: W-B L, X-X L. Study supervision: J X, Z-Y M, Y-H Q, X-X L. All authors read and approved the final manuscript.

\section{Acknowledgments}

We are grateful to the staff of the CDCs and TB dispensaries involved in this study in Henan province, China, and to all the participants for sharing their experiences with us.

\section{Author details}

${ }^{1}$ Institute for Tuberculosis Control and Prevention of Kaifeng prefecture, Henan Province, Kaifeng 475000, People's Republic of China. ${ }^{2}$ Henan Center for Disease Control and Prevention, Zhengzhou 450016, PRC. ${ }^{3}$ National Center for Tuberculosis Control and Prevention, Chinese Center for Disease Control and Prevention, 155 Changbai Road, Changping District, Beijing 102206, PRC

Received: 16 December 2014 Accepted: 10 March 2015

Published online: 24 March 2015

\section{References}

1. Faustini A, Hall AJ, Perucci CA. Risk factors for multidrug resistant tuberculosis in Europe: a systematic review. Thorax. 2006;61:158-63.

2. Diande S, Sangare L, Kouanda S, Dingtoumda BI, Mourfou A, Ouedraogo F, et al. Risk factors for multidrug-resistant tuberculosis in four centers in Burkina Faso, West Africa. Microb Drug Resist. 2009;15:217-21.

3. Tanrikulu AC, Abakay A, Abakay O. Risk factors for multidrug-resistant tuberculosis in Diyarbakir, Turkey. Med Sci Monit. 2010;16:PH57-62.

4. Hu Y, Mathema B, Wang W, Hoffner S, Kreiswirth B, Xu B. Prevalence of multidrug-resistant pulmonary tuberculosis in counties with different duration of DOTS implementation in rural China. Microb Drug Resist. 2008;14:227-32.

5. Jain A, Mondal R, Prasad R, Singh K, Ahuja RC. Prevalence of multidrug resistant Mycobacterium tuberculosis in Lucknow, Uttar Pradesh. Indian J Med Res. 2008;128:300-6.

6. Sanchez-Padilla E, Dlamini T, Ascorra A, Rusch-Gerdes S, Tefera ZD, Calain P, et al. High prevalence of multidrug-resistant tuberculosis, Swaziland, 2009-2010. Emerg Infect Dis. 2012;18:29-37.

7. World Health Organization. Multidrug and extensively drug-resistant TB (M/XDR-TB): 2010 global report on surveillance and response. Geneva, Switzerland: World Health Organization Press; 2010.

8. World Health Organization. Global tuberculosis control: WHO report 2011. Geneva, Switzerland: World Health Organization Press; 2011.

9. Ridzon R, Kenyon T, Luskin-Hawk R, Schultz C, Valway S, Onorato IM. Nosocomial transmission of human immunodeficiency virus and subsequent transmission of multidrug-resistant tuberculosis in a healthcare worker. Infect Control Hosp Epidemiol. 1997;18:422-3.

10. Cobo J, Asensio A, Moreno S, Navas E, Pintado V, Oliva J, et al. Risk factors for nosocomial transmission of multidrug-resistant tuberculosis due to Mycobacterium bovis among HIV-infected patients. Int J Tuberc Lung Dis. 2001;5:413-8

11. Vella V, Racalbuto V, Guerra R, Marra C, Moll A, Mhlanga Z, et al. Household contact investigation of multidrug-resistant and extensively drug-resistant tuberculosis in a high HIV prevalence setting. Int J Tuberc Lung Dis. 2011:15:1170-5.

12. Gilpin CM, Simpson G, Vincent S, O'Brien TP, Knight TA, Globan M, et al. Evidence of primary transmission of multidrug-resistant tuberculosis in the Western Province of Papua New Guinea. Med J Aust. 2008;188:148-52.

13. Vazquez-Gallardo R, Anibarro L, Fernandez-Villar A, Diaz-Cabanela D, Cruz-Ferro E, del Molino ML P, et al. Multidrug-resistant tuberculosis in a low-incidence region shows a high rate of transmission. Int J Tuberc Lung Dis. 2007;11:429-35.

14. Zhao M, Li X, Xu P, Shen X, Gui X, Wang L, et al. Transmission of MDR and XDR tuberculosis in Shanghai, China. PLoS One. 2009;4:e4370.

15. Hu Y, Hoffner S, Jiang W, Wang W, Xu B. Extensive transmission of isoniazid resistant $M$. tuberculosis and its association with increased multidrug-resistant TB in two rural counties of eastern China: a molecular epidemiological study. BMC Infect Dis. 2010;10:43.

16. Otero L, Krapp F, Tomatis C, Zamudio C, Matthys F, Gotuzzo E, et al. High prevalence of primary multidrug resistant tuberculosis in persons with no known risk factors. PLoS One. 2011;6:e26276.

17. World Health Organization. Guidelines for surveillance of drug resistance in tuberculosis (Second Edition). Geneva, Switzerland: World Health Organization Press; 2003.

18. Disease Control Bureau of the Ministry of Health, Department of Medical Administration of the Ministry of Health, Chinese Center for Disease Control and Prevention. Guidelines for implementing the national tuberculosis 
control program in China (2008). Beijing, China: Peking Union Medical College Press; 2009.

19. Wang GJ, Sleigh A, Zhou G, Jackson S, Liu XL. Nonbiologic risk factors of pulmonary tuberculosis among adults in Henan: a case-control study. Zhonghua Liu Xing Bing Xue Za Zhi. 2005;26:92-6.

20. Pang PT, Leung CC, Lee SS. Neighbourhood risk factors for tuberculosis in Hong Kong. Int J Tuberc Lung Dis. 2010;14:585-92.

21. Tekkel M, Rahu M, Loit HM, Baburin A. Risk factors for pulmonary tuberculosis in Estonia. Int J Tuberc Lung Dis. 2002;6:887-94.

22. Valim AR, Possuelo LG, Cafrune PI, Borges M, Ribeiro MO, Rossetti ML, et al. Evaluation and genotyping of multidrug-resistant cases of tuberculosis in southern Brazil. Microb Drug Resist. 2006;12:186-91.

23. Yang L, Wu DL, Guo HG, Liu JW. A study of the psychological and social factors in patients with pulmonary tuberculosis. Zhonghua Jie He He Hu Xi Za Zhi. 2003;26:704-7.

24. Suhadev M, Thomas BE, Raja Sakthivel M, Murugesan P, Chandrasekaran V, Charles N, et al. Alcohol use disorders (AUD) among tuberculosis patients: a study from Chennai, South India. PLoS One. 2011;6:e19485.

25. Zhao P, Li XJ, Zhang SF, Wang XS, Liu CY. Social behaviour risk factors for drug resistant tuberculosis in Mainland China: a meta-analysis. J Int Med Res. 2012;40:436-45.

26. Kondo $\mathrm{H}$, Morimoto $\mathrm{K}$. Effects of mental arithmetic stress on blood cell counts and the immune system. Environ Health Prev Med. 1996;1:76-9.

27. Benschop RJ, Nieuwenhuis EE, Tromp EA, Godaert GL, Ballieux RE, van Doornen LJ. Effects of beta-adrenergic blockade on immunologic and cardiovascular changes induced by mental stress. Circulation. 1994;89:762-9.

28. McQuistion HL, Colson P, Yankowitz R, Susser E. Tuberculosis infection among people with severe mental illness. Psychiatr Serv. 1997;48:833-5.

29. Ballieux RE. Impact of mental stress on the immune response. J Clin Periodontol. 1991;18:427-30.

30. Xu B, Jiang QW, Xiu Y, Diwan VK. Diagnostic delays in access to tuberculosis care in counties with or without the National Tuberculosis Control Programme in rural China. Int J Tuberc Lung Dis. 2005;9:784-90.

31. Jianzhao $H$, van den Hof $S$, Lin X, Yubang $Q$, Jinglong $H$, van der Werf MJ. Risk factors for non-cure among new sputum smear positive tuberculosis patients treated in tuberculosis dispensaries in Yunnan, China. BMC Health Serv Res. 2011;1:97.

32. Faurholt-Jepsen D, Range N, Praygod G, Jeremiah K, Faurholt-Jepsen M, Aabye MG, et al. Diabetes is a risk factor for pulmonary tuberculosis: a case-control study from Mwanza, Tanzania. PLoS One. 2011;6:e24215.

33. Kamboj M, Sepkowitz KA. The risk of tuberculosis in patients with cancer. Clin Infect Dis. 2006;42:1592-5.

34. Kim HR, Hwang SS, Ro YK, Jeon CH, Ha DY, Park SJ, et al. Solid-organ malignancy as a risk factor for tuberculosis. Respirology. 2008;13:413-9.

35. Fisher-Hoch SP, Whitney E, McCormick JB, Crespo G, Smith B, Rahbar MH, et al. Type 2 diabetes and multidrug-resistant tuberculosis. Scand J Infect Dis. 2008;40:888-93.

36. Manjourides J, Lin HH, Shin S, Jeffery C, Contreras C, Cruz JS, et al. Identifying multidrug resistant tuberculosis transmission hotspots using routinely collected data. Tuberculosis (Edinb). 2012;92:273-9.

\section{Submit your next manuscript to BioMed Central and take full advantage of:}

- Convenient online submission

- Thorough peer review

- No space constraints or color figure charges

- Immediate publication on acceptance

- Inclusion in PubMed, CAS, Scopus and Google Scholar

- Research which is freely available for redistribution 